\title{
Os projetos legislativos de iniciativa popular no Brasil
}

\author{
Draft bills of popular initiative in Brazil
}

\begin{abstract}
Bruna Bottero Corrêa
Graduada em Direito pela Universidade Federal do Rio Grande (2014) e Mestra em Direito e Justiça Social pela Universidade Federal do Rio Grande (2018). brunabotterocorrea@gmail.com

Daniel Lena Marchiori Neto

Universidade Federal de Pelotas (UFPel) Professor Adjunto da Faculdade de Administração e de Turismo da Universidade Federal de Pelotas (UFPel) e Professor Permanente do Mestrado em Direito e Justiça Social da Universidade Federal do Rio Grande (FURG). Doutor em Direito pela Universidade Federal de Santa Catarina

(UFSC).

danielmarchiorineto@gmail.com

Caroline Ferri

Universidade do Estado do Rio de Janeiro (UERJ) Graduada em Direito pela Universidade do Vale do Itajaí e em Filosofia pela Universidade Federal de Santa Catarina. Mestrado em Direito pela Universidade Federal de Santa Catarina. Doutorado em Direito pela Universidade Federal de Santa Catarina. Professora da Universidade do Estado do Rio de Janeiro (UERJ). carolineferri@gmail.com
\end{abstract}

Resumo: Este trabalho tem por objetivo analisar os projetos de iniciativa popular legislativa (IPL) no Brasil, esclarecendo sua situação e levantando seus pontos críticos. Inicialmente, será narrado o contexto de cada projeto de Iniciativa Popular e, posteriormente, avaliado seu trâmite institucional. Os dados levantados indicam um esvaziamento da IPL tanto em aspectos procedimentais como de mérito.

Palavras-chaves: Iniciativa Popular Legislativa. Projetos legislativos. Procedimento.

Abstract: This paper analyzes the draft bills of federal popular initiative (FPI) in Brazil, clarifying their situation and raising critical points. Initially, the context of each Popular Initiative project will be narrated and then its institutional framework will be evaluated. The results show a depletion of FPI in both procedural and merit aspects.

Keywords: Popular Legislative Initiative. Draft Bills. Procedure.

\section{Introdução}

Recentemente, a Câmara dos Deputados foi acusada de desfigurar um projeto de iniciativa popular. O projeto foi aprovado, mas não sem antes sofrer modificações pertinentes que, não por menos, deram origem à crítica. A forma como o Congresso Nacional interviu no conteúdo do projeto levantou o questionamento do quanto ele pode ser modificado, gerando um impasse dentre os próprios parlamentares. 
Ao referir a situação, que já parece suficientemente absurda, o presidente da Câmara dos Deputados à época manifestou: "Não podemos aceitar que a Câmara se transforme em cartório carimbador de opiniões de partes da sociedade" (AMORIM, 2017, n.p.). A referida manifestação demonstra, no mínimo, uma forte resistência ao direito à Iniciativa Popular Legislativa (IPL) e o que ela pode proporcionar.

A IPL consiste na propositura de um projeto de lei pelos cidadãos eleitores mediante o atendimento de alguns requisitos legais, dentre eles a exigência constitucional de que os projetos sejam assinados, por não menos de $1 \%$ do eleitorado nacional, percentual exigido para iniciativa em âmbito federal, distribuídos em pelo menos cinco estados, com não menos de $0,3 \%$ de seus eleitores. Portanto, o projeto que alcança o número de assinaturas exigidas representa a opinião de parte significativa da sociedade. $\mathrm{O}$ rito procedimental estabelece outra série de exigências que a tornam um processo complexo, porém democrático. Apesar do esforço da legislação, inclusive da Constituição em torná-la um instrumento um legítimo instrumento democrático, ao alcançar o Congresso, parece ser desprezada.

Ao declarar algo como "nós (representantes) não somos os carimbadores do povo" (AMORIM, 2017, n.p.), o presidente da Câmara deixa transparecer a imaturidade democrática do Parlamento. Afinal, a Iniciativa Popular Legislativa pode ser considerada o meio jurídico pelo qual, no Estado moderno, o povo pode intervir nas decisões políticas decididas no âmbito do Poder Legislativo.

Schumpeter (1961) discorre que uma vez eleitos, os políticos não têm nenhum compromisso com o povo. O governo não é do povo, é eleito pelo povo. Eventualmente, o bom político ilude, maneja o argumento democrático de que o governo é do povo para tentar manterse no poder. A Iniciativa Popular serviria para romper essa lógica. Através dela, em tese, o povo por direito participa do processo legislativo assumindo o controle, fiscalizando e agindo. É imprescindível para qualquer movimentação social em busca de novos direitos e readequação das obrigações, deter, o quanto possível, condições de atuar como legislador. O Parlamento é um espaço adequado enquanto instituição, porém muitas vezes distante das movimentações populares. O desafio é justamente, aproximar o povo dessa via institucional.

O trabalho divide-se em duas seções. Inicialmente, será narrado o contexto de cada projeto de Iniciativa Popular e, posteriormente, avaliado seu trâmite institucional. A pesquisa mostrará que o procedimento de iniciativa popular tem sido desvirtuado tanto em aspectos procedimentais quanto de mérito. 


\section{Os projetos de lei de iniciativa popular no Brasil}

A Iniciativa Popular foi incluída no ordenamento jurídico brasileiro a partir da Constituição de 1988 (CAVALCANTE FILHO, 2017) e regulamentada pela Lei Ordinária n. 9709/98. Antes mesmo de iniciar a apresentação das experiências em Iniciativa Popular no Brasil, cabe antecipar alguns esclarecimentos.

Através de pesquisa na plataforma digital da Câmara dos Deputados, não foi possível reconhecer de imediato os projetos de Iniciativa Popular, ao menos por autoria. Por vezes, em alguns projetos a ementa menciona que foram recebidas as assinaturas para tramitar como Iniciativa, enquanto em outros não há nenhuma alusão. Por essa razão, “quando se indaga se a iniciativa popular já foi exercida no Brasil em âmbito federal, a resposta tende a variar" (SANTOS, 2009, p. 89). No mesmo sentido, as Leis $n^{\circ}$ 8.930/1994, 9.840/1999 e 11.124/2005 não podem ser consideradas como de iniciativa popular. Seus respectivos projetos "tiveram sua iniciativa na Câmara dos Deputados validada a partir da assinatura de seu texto por um deputado ou pelo Presidente da República" (SANTOS, 2008, p. 16).

É importante destacar que a atribuição de autoria à deputado é obrigatória, segundo Regimento Interno da Câmara dos Deputados, que prevê a necessária atribuição de responsabilidade pela tramitação a um dos deputados da Casa recebedora do projeto. A exigência não está prevista na lei ordinária regulamentadora, tampouco na Constituição Federal e parece estar na contramão do propósito da Iniciativa Popular. Daí decorre a dificuldade de encontrar no site da Câmara a identificação clara e precisa de quais projetos de lei são de Iniciativa Popular.

Diante do impasse para identificar os projetos tramitados e em tramitação, oriundos de Iniciativa Popular no Brasil, não restou alternativa senão encaminhar mensagem eletrônica à Câmara dos Deputados através do espaço dedicado à comunicação e esclarecimentos do próprio site. A resposta retornada por e-mail (BRASIL, 2016a) indicou cinco projetos finalizados e três em tramitação.

Os projetos informados pela Câmara são reconhecidos como Iniciativas Populares. O site também disponibiliza alguns dos chamados dossiês, arquivos de análise que reúnem, de forma documentada, o trâmite do processo legislativo. Desta maneira, é possível identificar o cumprimento das etapas procedimentais, revelando o efetivo funcionamento do instrumento.

De acordo com a casa legislativa, no Brasil, os projetos de iniciativa popular tramitados são o Projeto de Lei (PL) 2710/1992 sobre moradia popular, o PL 4146/1993 sobre crime hediondo, o PL 1517/1999 sobre compra de votos, o PLP 518/2009 conhecido como Ficha 
Limpa e o PL 1472/2007 conhecido como de olho no imposto, todos aprovados em lei. Em tramitação, encontram-se o PL 7053/2006, cujas assinaturas foram geradas pelo Movimento Gabriela Sou Da Paz, o PLP 321/2013, conhecido por Saúde Mais Dez e o PL 4850/2016, que propõe as chamadas Dez Medidas de Combate à Corrupção (BRASIL, 2016a).

A iniciativa da moradia popular (Projeto de Lei Ordinária 2710/1992) culminou na criação da Lei $n^{o} 11.124$ de 2005 (BRASIL, 2005, p. 1). De acordo com a data de publicação do projeto (BRASIL, 1992b), trata-se da primeira Iniciativa Popular Legislativa a ser proposta no Brasil. Em contrapartida, foi a mais longa em tempo de tramitação. É também conhecido como o projeto que propôs a criação do Sistema Nacional de Habitação e Interesse Social SNHIS e considerado como o "único caso de iniciativa popular propriamente dita" (CAVALCANTE FILHO, 2017, p. 19) no Brasil, ou que pelo menos foi assim considerado pelo Congresso, por ter recebido identificação clara e no registro processual como projeto de iniciativa popular.

O registro no dossiê documentativo do projeto, como de Iniciativa Popular, atribuiu o caráter simbólico, importante para enfatizar que o povo foi o verdadeiro autor da lei. No entanto, desde logo, essa iniciativa enfrentou dificuldades relacionadas à competência em função da matéria.

Os “[...] projetos de lei do legislativo não poderiam vincular despesas além das áreas de saúde e educação previstas na Constituição e também não poderiam criar conselhos ou órgãos, cuja atribuição seria exclusiva do Executivo [...]" (LIN, 2010, p. 90). A previsão contida no art. $61, \S 1^{\circ}$, II, em especial as alíneas $b$ e $e$, da CRFB (BRASIL, 1988, p. 10) sugere que de fato o projeto avançou sobre a competência privativa do Executivo ao tratar de matéria orçamentária. O plano proposto pela Iniciativa vinculava orçamento para a demanda de moradia popular através da criação de um fundo específico, gestado por um conselho próprio. Desse modo, as áreas orçamentária e administrativa-organizacional públicas foram afetadas.

Nessa mesma linha de entendimento, segundo Paz (1996), a resistência política institucional ao projeto foi devida ao entendimento de que moradia seria matéria de políticas públicas, devendo ser proposta, portanto, pela Presidência da República. Ao Legislativo, caberia tratar somente de questões que não envolvessem projetos políticos sociais de governo. Orçamentos de responsabilidade do Executivo não poderiam ser pauta de projetos populares. Por outro lado, a rigor, políticas públicas seriam aquelas direcionadas a todos cidadãos, enquanto as sociais, por sua vez, cuidariam de interesses coletivos mais restritos, como os do movimento por moradia. $\mathrm{O}$ fundo planejado por essa Iniciativa estaria vinculando orçamentos 
a serem destinados para uma política social, direcionada a um nicho societário específico, não adentrando, portanto, no campo das políticas públicas.

Ribeiro Junior (2005) defende que a vinculação orçamentária estaria a serviço de uma necessidade decorrente de um desejo maior, de um projeto mais amplo, que tem por fundamento um direito fundamental, qual seja, à moradia digna. A ameaça ao princípio da dignidade voltado à moradia seria uma fundamentação relativamente forte a ponto de colocar fim à discussão da competência, priorizando o atendimento a esse direito fundamental.

Contudo, no que tange à competência privativa sobre a matéria, apesar de toda sorte de argumentação doutrinária, a Câmara dos Deputados enfatizou no $e$-mail que

\footnotetext{
[...] de acordo com a Constituição Federal de 1988 (art.14, III e art.61, §2º), projetos de iniciativa popular podem ser apresentados à Câmara dos Deputados desde que cumpram as seguintes exigências: disponham sobre temas que não sejam de iniciativa privativa do Presidente da República; contenham a assinatura de, no mínimo, um por cento do eleitorado nacional, originárias de, pelo menos, cinco Estados, com não menos de três milésimos dos eleitores de cada um deles (BRASIL, 2016a, grifo nosso).
}

Ainda assim, a situação irregular não foi impedimento para que fosse dado andamento ao projeto. A questão relativa à matéria não foi obstáculo para o prosseguimento da tramitação. Quanto às assinaturas, a Secretaria-Geral manifestou à Presidência da Mesa a impossibilidade de verificação da condição de eleitor dos assinantes por incompletude do banco de dados da Justiça Eleitoral. Apesar disso, opinou pela aceitação do projeto (BRASIL, 1992a).

Não é possível constatar ao certo qual foi o motivo, mas as duas circunstâncias de falha no atendimento das exigências legais - quanto à matéria e para com as assinaturas - por fim, foram sanadas através da flexibilização do rigor procedimental. Ainda que as transgressões não tenham afetado o recebimento da Iniciativa - ao contrário, acabaram favorecendo -, o fator perverso é a interferência dos parlamentares no rito, já que ao fim o procedimento legal foi reconsiderado. A lei e o Regimento foram superados pela arbitrariedade. Além disso, o projeto original foi substituído integralmente pela chamada emenda substitutiva global, de iniciativa parlamentar (CAVALCANTE FILHO, 2017).

O projeto popular foi adaptado ao trabalho que já vinha sendo executado pelos parlamentares. Através de apensamentos e alterações realizadas durante a tramitação, a casa legislativa promoveu a aproximação de outros projetos já em tramitação com o promovido pelo povo, facilitando seu recebimento, em que pese os requisitos legais procedimentais não tenham sido inteiramente respeitados.

Dando continuidade à análise, o PL 4146/1993, que tratou da ampliação do rol de crimes hediondos, foi o primeiro projeto de Iniciativa Popular a se tornar lei no Brasil, de acordo com 
a data de publicação da correspondente Lei Ordinária n ${ }^{\circ}$ 8.930/94 (BRASIL, 1994). O primeiro e segundo projetos de Iniciativa Popular se distanciam pela celeridade na tramitação. Da propositura à aprovação, o primeiro foi de longe o mais demorado, enquanto o segundo, o mais célere.

A segunda Iniciativa Popular derivou da mobilização em torno de tentativas de controlar a violência. Envolveu um acontecimento famoso, de grande repercussão e comoção social. A indignação trouxe à tona, novamente, a discussão sobre os níveis de punição, dando origem ao projeto

"[...] cuja campanha para coleta de assinaturas foi encabeçada pela escritora Glória Perez, juntamente com outras mães de vítimas da violência, objetivando a inclusão do crime de homicídio qualificado como hediondo após o assassinato da sua filha Daniella Perez" (LEITE; MAGALHÃES, 2013, p. 2229).

A vítima era atriz de uma novela de grande popularidade, tendo sido assassinada por um colega de trabalho (também ator). Ambos atuavam na produção com roteiro escrito pela mãe da vítima. O país inteiro restou comovido diante da tragédia. Não obstante a crueldade do crime, a percepção social sobre o tema foi fortemente influenciada pela mídia. Nesse contexto,

\footnotetext{
"carregada de questões comoventes, que cercam a todos, principalmente no que tange ao clamor de justiça, há de se considerar que a mídia, além de tudo, tenha atualizado a memória da sociedade em torno do fato crime por causa de um crime, e com isso, tenha despertado a atenção da sociedade para seu próprio funcionamento e para a necessidade de proteção dos valores pelos quais decide viver, inclusive revitalizando as práticas institucionais" (LEITE; MAGALHÃES, 2013, p. 2237).
}

A memória social revive o impactante crime através do apelo midiático. Com isso, o instrumento parece ter sido reavivado como prática institucional funcional capaz de sobrepujar o sofrimento e capacitar o cidadão ou as vítimas indiretas - a sociedade em geral - a realizar um ato que converta o sentimento de dor e impotência diante do crime em algo que acarrete uma consequência legal punitiva para os que o cometerem.

A autoria deveria ter sido encaminhada a algum deputado, em atendimento ao disposto no Regimento Interno da Câmara dos Deputados (RICD). Porém, o registro foi atribuído ao Poder Executivo. O direito penal está dentre os temas de competência privativa da União, conforme prevê o art. 22, inciso I, da CRFB (BRASIL, 1988, p. 5). A reunião do projeto inicial a outros projetos já em tramitação culminou na aprovação da lei, sem que para isso fosse necessária a readequação do projeto aos requisitos, dentre eles o da matéria.

No dossiê, após essa primeira etapa, simplesmente não houve menção alguma à Iniciativa, nem mesmo amostra de assinaturas, mas apenas pareceres de autoridades opinando pelo enrijecimento da pena em combate ao suposto aumento da violência. O texto inicial não apresentava o homicídio qualificado, mas essa emenda parece ter se tornado o foco. O projeto 
propunha punições aplicáveis à conduta de homicídio praticado por comando de grupos de extermínio, ainda que envolvam um só agente e de homicídio qualificado, todos classificados pela proposta como crimes hediondos (BRASIL, 1993).

A demanda despertou interesse político parlamentar e o projeto foi absorvido pelas proposições que tramitavam em torno do assunto. O Executivo acabou assumindo a tarefa de apresentar o projeto, muito embora seu dossiê não contivesse nenhuma das assinaturas. Da sua leitura, observa-se ainda que o projeto recebeu apoio de órgãos e agentes políticos, mas os eleitores assinantes não constam nem por amostragem (BRASIL, 1993). Todavia, uma vez assinado pelo Poder Executivo, o projeto não poderia ser recusado pela falha na exigência das assinaturas.

A aceitação como projeto de Iniciativa Popular, por parte da Câmara, foi apenas alusiva. A Iniciativa pressionou e incentivou trabalhos que, em parte, já se encontravam em andamento. O fator popular parece ser aproveitado, guardadas proporções, como impulso utilitarista aos anseios parlamentares.

A Iniciativa Popular contra a compra de votos (PL 1517/1999) foi promovida pelo Movimento de Combate à Corrupção Eleitoral (MCCE). A lei originada (Lei n. 9840/99) define as situações de captação de sufrágio, determinando a aplicação de multa e cassação do registro de candidatura do candidato que a cometer, isto é, doar, oferecer ou prometer bem ou vantagem pessoal em troca do voto, no período que se inicia com a candidatura até a eleição (MCCE, 2016).

Com o slogan "voto não tem preço, tem consequências!" (MCCE, 2016, p. 3), o movimento defendeu que o conteúdo da Lei n. 9840/99 "possui um papel fundamental para a conquista de um sistema político mais democrático ao combater a compra de votos e o uso eleitoral da máquina administrativa" (MCCE, 2016, p. 12). Em resumo, a lei resultante alterou o Código Eleitoral, tornando a captação ilícita de sufrágio crime eleitoral com pena de cassação e multa ao candidato que a cometer (BRASIL, 1999b).

No que tange ao procedimento, o projeto foi proposto antes de angariar o mínimo legal das assinaturas (BRASIL, 1999a). Mais uma vez, os requisitos não atendidos foram deixados de lado e substituídos pela iniciativa parlamentar. A exigência constitucional do mínimo de $1 \%$ do eleitorado nacional foi flexibilizada em detrimento da celeridade, para que o projeto fosse aprovado e a consequente lei gerasse efeitos antes da eleição seguinte.

No caso do Projeto de Lei Complementar 518/2009, que gerou a Lei complementar 135/2010 (a conhecida Lei da Ficha Limpa), mais uma vez, o Movimento de Combate à Corrupção Eleitoral (MCCE) foi seu articulador. O "segundo projeto de iniciativa popular 
anticorrupção que virou lei” (MCCE, 2016, p. 13) instituiu a chamada Ficha Limpa, obrigatória para os candidatos nas eleições em todos os níveis. Na tentativa de moralizar o exercício da atividade política, a sociedade civil organizou-se para propor ao Congresso Nacional um projeto de lei (complementar) impondo a inelegibilidade das pessoas que fossem condenadas por um órgão colegiado, tanto pela prática de improbidade administrativa, quanto pelo cometimento de determinados delitos (CAVALCANTE FILHO, 2017).

A lei aumentou para oito anos o período de inelegibilidade de agentes políticos que cometeram ou vierem a cometer crimes de natureza eleitoral, e suspendeu a exigência do trânsito em julgado nos casos em que a representação for julgada procedente pela Justiça Eleitoral (BRASIL, 2010). Após discussões acerca de sua inconstitucionalidade (BRASIL, 2012c), especialmente no que tange as consequências punitivas e cerceadoras antes mesmo do trânsito em julgado, foi "reconhecida internacionalmente, [...] validada em fevereiro de 2012 pelo Supremo Tribunal Federal (STF)" e "declarada plenamente constitucional” (MCCE, 2016, p. 13).

O projeto Ficha Limpa, para os propositores, deveria ser aprovado o quanto antes devido à proximidade das eleições. Tendo em vista a pressão popular, o projeto acabou sendo recebido e adotado pelo Senado Federal. Neste caso, em específico, o nível de celeridade na tramitação, com a consequente aprovação do projeto, foi alto.

Com relação às Iniciativa Populares Legislativas que trataram de crimes eleitorais, segundo a pesquisa de Melchiori (2011), o procedimento do projeto contra a compra de voto e pela ficha limpa apresentaram pelo menos duas situações que atravancaram o processo, com base nos relatos dos envolvidos com o recolhimento das assinaturas e assinantes que acompanharam a tramitação: a exigência do número do título de eleitor, pois a maior parte dos eleitores não porta cotidianamente o documento e a resistência dos próprios congressistas em colaborar para uma rápida tramitação.

Apesar dos resultados comemorados pelos movimentos, como no caso em tela e no anterior, em que a celeridade foi superestimada, a vitória alcançada desprestigia o rigor técnico relativo à coleta das assinaturas. Do mesmo modo, ao alterar substancialmente o projeto, relega a segundo plano a projeção das ideias articulada proposta pelo povo. A impressão é a de que basta pressionar os representantes para que então passem a tratar dos temas em questão (CAVALCANTE FILHO, 2017).

A lei n. 12741/2012 originada do projeto de lei de iniciativa popular 1472/2007 conhecido como De olho no imposto - criou medidas para que os consumidores sejam 
esclarecidos acerca dos impostos que incidem sobre mercadorias e serviços, através do documento fiscal ou em painel eletrônico visível no ato da compra (BRASIL, 2012b, p. 1-2). A autoria do projeto é atribuída ao Senado Federal. Embora os projetos de Iniciativa Popular devam ser protocolados na Câmara dos Deputados, neste caso, novamente, ainda que possuindo as assinaturas, o projeto iniciou no Senado. A negligência parlamentar com o seu procedimento demonstra que, na prática, a Iniciativa Popular Legislativa, ou seu procedimento, é considerado tão irrelevante que sequer importa em qual casa deva começar a tramitar.

No que tange aos projetos em tramitação, o promovido pelo Movimento Gabriela Sou da Paz surgiu de outra tragédia, desta vez, ocorrida no metrô do Rio de Janeiro/RJ, por uma bala perdida que matou uma jovem. Novamente, o tema da punibilidade irrompe. Os pais da vítima foram responsáveis pela criação do movimento, pelo qual

[...] convocaram a sociedade civil a subscrever o abaixo-assinado que teve como objetivo o recolhimento de mais de um milhão e duzentas mil assinaturas, para respaldar o encaminhamento ao Congresso Nacional de emenda popular modificando a legislação penal em vigor (BRASIL, 2006, p. 3).

Apesar da citação transcrita tratar o projeto como emenda, a proposição é uma Iniciativa Popular Legislativa para a criação de lei visando a emendar legislação existente. A proposta (Projeto de Lei Ordinária 7053/2006) busca retirar o benefício relativo à fixação de pena ao autor de crime continuado quando se tratar de cometimento de crime hediondo, tortura e genocídio. Proíbe também a apelação em liberdade para aquele que for condenado nos crimes mencionados e por tráfico de drogas, bem como o indulto, em caso de crime de tortura. Pretende ainda revogar a possibilidade de protesto por novo júri. O projeto acabou integrando o grupo de proposições em tramitação que visam a alterar o Código Penal.

A Iniciativa Popular em tramitação, o Projeto de Lei Complementar 321/2013 conhecido como Saúde Mais Dez, busca a alteração dos dispositivos da Lei Complementar existente que regulamenta a CRFB no que tange à aplicação, pela União, de montantes financeiros para a saúde. A Iniciativa defende a aplicação de recursos iguais ou superiores a dez por cento das receitas correntes brutas da União para esse campo. O investimento seria destinado exclusivamente para ações e serviços públicos de saúde.

Foi apensada ao PL 123/2012, tramitando uma proposta idêntica, qual seja, a aplicação, pela União, do mínimo de dez por cento de suas receitas brutas em ações e serviços de saúde. O projeto popular teve sua autoria atribuída à Comissão de Legislação Participativa (CLP). A Iniciativa Popular, neste caso, foi totalmente desconsiderada, pois tratada como sugestão mesmo com toda sorte de regulamentação específica. Resta saber se a Câmara recebeu um projeto articulado pelo povo ou se, não levando em conta o teor, não fez a diferenciação devida. 
O documento encaminhado à Presidência da Câmara (BRASIL, 2013) revela que a iniciativa teria sido recebida como sugestão e revertida em projeto pela Comissão de Legislação Participativa. Em contrapartida, registra o número de assinaturas que a acompanharam. Para apresentar uma sugestão à referida Comissão, basta à entidade que a propôs assiná-la, sendo desnecessário o recolhimento das assinaturas de seus membros individualmente. Ao contrário, a coleta individual é requisito da Iniciativa Popular Legislativa, que prioriza a ação individual dos cidadãos. Pessoas jurídicas não podem propô-la, somente sugestão legislativa à CLP.

Seria um contrassenso buscar assinaturas para instruir uma sugestão. De acordo com o RICD, uma Iniciativa Popular que não atenda aos requisitos procedimentais deverá ser devolvida ao autor para a devida correção. Alternativamente, caso os problemas forem de natureza meramente formal, deve ser encaminhada à Comissão de Constituição e de Justiça e de Cidadania (CCJC) para a correta adequação.

A iniciativa pode ter sido entregue com as respectivas assinaturas, mas não em forma de projeto. Embora reconhecida como uma Iniciativa Popular, não teria sido entregue à Mesa da Câmara e, ao que tudo indica, foi recebida como sugestão pela Comissão de Legislação Participativa (CLP) e por esta adaptada a projeto de lei. Essa atitude ignora por completo o procedimento, escancarando a incongruência técnica.

Não diferentemente das anteriores, esta Iniciativa Popular acabou por ser misturada à atividade parlamentar tradicional, o que uma vez mais, desqualifica seu propósito. Esta situação chegou ao limite no caso da Iniciativa Popular conhecida como Dez medidas de combate à corrupção. O PL 4850/2016 é oriundo de iniciativa popular que teve como principal impulsionador o Ministério Público, buscando resgatar novamente a preocupação em torno de mudanças legislativas que atendam, de forma preventiva e punitiva, do combate à corrupção. Trata de estabelecer medidas direcionadas aos crimes contra o patrimônio público, em especial, o enriquecimento ilícito de agentes públicos. Para tanto, propõe alterar leis vigentes atinentes. No entanto,

[...] a versão apresentada não é idêntica àquela que foi objeto da coleta de assinaturas [...]. A versão divulgada pelo MPF continha até mesmo um inusitado "Anteprojeto (sic) de Emenda Constitucional", para tratar da execução provisória da pena, mesmo sabendo-se que o ordenamento pátrio não admite a iniciativa popular de emendas à Constituição (CAVALCANTE FILHO, 2017, p.26).

Já em tramitação, chegou a ser aprovado pela Câmara como um pacote anticorrupção até ser barrado pelo Supremo Tribunal Federal (STF) quando estava à espera de apreciação pelo Senado. O STF, uma vez provocado mediante ação proposta por deputado, determinou, em 
decisão liminar no Mandado de Segurança n ${ }^{\circ} 34.530$, que o projeto retornasse ao ponto inicial da tramitação, para reenquadramento em procedimento próprio. Segue a ementa do julgado:

\begin{tabular}{|c|c|}
\hline $\begin{array}{l}\text { REITO CONSTITUCIONAL. } \\
\text { RLAMENTAR À OBSERVÂ }\end{array}$ & 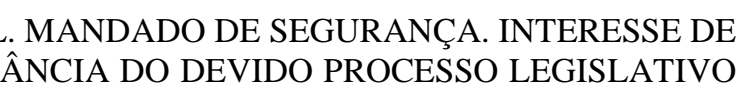 \\
\hline CONSTITUCIONAL. & CONTROLE PREVENTIVO \\
\hline CONSTITUCIONALIDADE & ADMITIDO. ANTEPROJETO DE LEI DE \\
\hline INICIATIVA POPULAR AUTU & UADO COMO PROJETO DE LEI DE INICIATI \\
\hline RLAMENTAR. DESVIRT & DA ESSÊNCIA \\
\hline VIOLAÇÃO AOS ARTIGOS & 14,111, E $61, \S 2^{\circ}$, DA CONSTITUIÇÃO. \\
\hline VULNERAÇÃO & DEMOCRÁTICO. \\
\hline $\begin{array}{l}\text { INCONSTITUCIONALIDADE } \\
\text { (BRASIL, 2016b, p. 1). }\end{array}$ & FORMAL. MEDIDA LIMINAR DEFERIDA \\
\hline
\end{tabular}

Até o oportuno advento da discussão em tela, "a assunção de autoria dos projetos por parlamentares não gerou maiores controvérsias, e tem, portanto, reforçado a ideia de que os projetos de iniciativa popular não têm regime especial de tramitação" (CAVALCANTE FILHO, 2017, p. 26). Cavalcante (2017), sugere uma classificação para as IPL, sendo aquelas assumidas por parlamentares "falsas" ou "impróprias" (p. 20). A decisão do Ministro Relator Luiz Fux indicou que a tramitação deveria retornar ao ponto de partida, respeitando o procedimento referente ao rito próprio destinado às Iniciativa Populares, justamente por entender que houve um desvirtuamento da tramitação e total desconfiguração do texto original. Neste caso, a decisão acabou

\begin{abstract}
"determinando, por consequência: $(i)$ o retorno do Projeto de Lei da Câmara ${ }^{\circ}$ 80/2016, em tramitação no Senado Federal, à Casa de origem e (ii) que a Câmara dos Deputados autue o anteprojeto de lei anticorrupção encaminhado àquela Casa legislativa com as assinaturas de 2.028.263 (dois milhões, vinte e oito mil e duzentos e sessenta e três) eleitores, como Projeto de Iniciativa Popular, observando o rito correlato previsto no seu Regimento Interno, consoante os artigos 14, III, e 61, § $2^{\circ}$, da Constituição" (BRASIL, 2016b, p. 11).
\end{abstract}

A respeito, o Presidente da Câmara em exercício manifestou que "poderia enviar o projeto de combate à corrupção de volta aos procuradores que lideraram a coleta de 2 milhões de assinaturas para que elas fossem checadas" (MARQUES, 2016). Ocorre que, como visto, a casa legislativa é a responsável por conferir as assinaturas, tarefa precípua da Secretaria-Geral da Mesa Diretora da Câmara.

O Presidente da Câmara também declarou que "isso [o projeto ser assinado por um parlamentar] é feito com todas as iniciativas populares diante da impossibilidade de a Câmara checar a veracidade de milhares de assinaturas" (MARQUES, 2016), ignorando o fato de ambos quesitos serem, inclusive, disposições regimentais. No entanto, volta atrás em outra oportunidade manifestando que, ainda assim, "[...] é possível acionar os TREs (Tribunais Regionais Eleitorais) de todo o país para fazer isso" (MARQUES, 2016). Por fim, sobre este último ponto, há que se salientar, novamente de acordo com o disposto no RICD, que a Câmara 
é a responsável por fazer a conferência das assinaturas, ainda que com as informações prestadas pelos demais órgãos. Conforme decisão do STF, o posicionamento jurisprudencial é avesso a qualquer tipo de representação do projeto de iniciativa popular por parlamentar, conforme trecho:

\begin{abstract}
Em primeiro lugar, o projeto subscrito pela parcela do eleitorado definida no art.61, $\S$ $2^{\circ}$, da Constituição deve ser recebido pela Câmara dos Deputados como proposição de autoria popular, vedando-se a prática comum de apropriação da autoria do projeto por um ou mais deputados. A assunção da titularidade do projeto por parlamentar, legitimado independente para dar início ao processo legislativo, amesquinha a magnitude democrática e constitucional da iniciativa popular, subjugando um exercício por excelência da soberania pelos seus titulares aos meandros legislativos nem sempre permeáveis às vozes das ruas. Nesse ponto, é relevante destacar que desde 1988 não houve nenhum projeto sequer autuado formalmente como de iniciativa popular na Câmara dos Deputados, atestando não apenas o completo desprestígio com que este instrumento democrático é tratado, mas também a eliminação de qualquer efetividade das normas constitucionais que regem o tema. Vale lembrar que a autuação do anteprojeto de iniciativa popular como se apresentado à Casa por parlamentar, tem consequências relevantes em termos procedimentais, malferindo o devido processo legislativo constitucional adequado (BRASIL, 2016b, p. 4-5, grifo nosso).
\end{abstract}

Um deslocamento sequer de autoria seria suficiente para desvincular a titularidade do povo. Essa determinação regimental prejudica o fator simbólico da soberania popular, materializada no projeto proposto pela IPL. Este ponto, objeto de crítica do Supremo, parece ser bem coerente e de extrema relevância para o procedimento da IPL, em que pese esteja regulamentado pela previsão regimental. A atribuição de autoria se não inconstitucional, como declara o STF, é no mínimo, contraproducente à finalidade da IPL, depreciando-a.

Uma vez assumida por um ou mais parlamentares, a condução do projeto leva inevitavelmente ao natural desligamento dos propositores de origem, como se a partir do início da tramitação o envolvimento popular passasse a ser irrelevante. O elemento iniciador ativo do projeto, que é o povo, é ignorado após seu recebimento pela Câmara, o que o leva a ser transformado e, por fim, identificado como mais um projeto parlamentar.

Além disso, outro ponto fundamental de discussão, deve-se ao quadro de modificação substancial do projeto, fora dos limites propostos pela Iniciativa Popular, fruto de uma articulação promovida exclusivamente pelo parlamento. Dentre as observações apontadas pela sentença, constam a crítica às alterações substanciais, principalmente aquelas realizadas através de emenda parlamentar:

Há apenas simulacro de participação popular quando as assinaturas de parcela significativa do eleitorado nacional são substituídas pela de alguns parlamentares, bem assim quando o texto gestado no consciente popular é emendado com matéria estranha ou fulminado antes mesmo de ser debatido, atropelado pelas propostas mais interessantes à classe política detentora das cadeiras no Parlamento nacional [...]. Em semelhante prisma, o Plenário desta Corte já entendeu ser vedada pela Constituição a prática de introdução de matéria estranha ao conteúdo de medida provisória no 
processo legislativo destinado à sua conversão, por meio de emenda parlamentar, precisamente por vulnerar o princípio democrático e o devido processo legislativo. (BRASIL, 2016b, p. 6).

As alterações promovidas pelos parlamentares, de certa forma, teriam inibido medidas de investigações anticorrupção que a Iniciativa Popular projetou inicialmente. Posicionamentos contrários à decisão, levantam o questionamento acerca da competência do STF para esse tipo de interferência no Poder Legislativo e que a decisão do Tribunal, no fim das contas, poderia consistir em interesse próprio de seus membros, pois uma das emendas atacadas teria intenção de coibir o abuso de poder dos investigadores públicos. Por outro lado, o Supremo não fez mais do que atender ao dever de provimento jurisdicional. Quanto a estes contrapontos, a decisão adotou o seguinte posicionamento:

"[...] é de se ressaltar a impropriedade da visão atávica que qualifica as discussões sobre transgressões a normas regimentais como questões interna corporis, imunes ao controle judicial. [...] Em primeiro lugar, as disposições regimentais consubstanciam, em tese, autênticas normas jurídicas e, como tais, são dotadas de imperatividade e de caráter vinculante. Sua violação, ademais, habilita a pronta e imediata resposta do ordenamento jurídico. Nesse cenário, é inconcebível a existência de normas cujo cumprimento não se possa exigir coercitivamente. Não há aqui outra alternativa: $(i)$ ou bem as normas regimentais são verdadeiramente normas e, portanto, viabilizam sua judicialização, (ii) ou, a rigor, não se trata de normas jurídicas, mas simples recomendações, de adesão facultativa pelos seus destinatários. Este último não parece ser o caso" (BRASIL, 2016b, p. 6).

Neste caso específico, pela primeira vez, o judiciário foi provocado acerca do tratamento institucional-procedimental prestado a Iniciativa Popular. Em projetos anteriores, como visto, foi atribuída a diversos agentes, diversas vezes colocada em desacordo com o RICD e inclusive, sem nenhuma menção nos registros oficiais aos seus incentivadores e assinantes, irregularidades que não foram questionadas. Nesse aspecto, a sentença igualmente esclarece suas consequências jurídicas e delimitações:

A fim de evitar o questionamento da validade de todos os atos normativos editados por rito diverso, revela-se adequada a modulação dos efeitos da decisão para abranger apenas os projetos de lei ainda não publicados após sanção do Presidente da República ou derrubada do veto, inclusive o projeto de lei impugnado no presente feito (BRASIL, 2016b, p. 10).

Sobram confusões e falta clareza, tanto para os iniciadores da proposição, como também por parte dos poderes, o que revela a dificuldade institucional e não só cultural da utilização da Iniciativa Popular. A transparência com relação à origem popular do projeto é de extrema relevância para dar validade ao seu exercício. A conferência das assinaturas, por sua vez, é vital para a sua legitimidade. Na prática, a atuação parlamentar pode ser extremamente invasiva, o que parece nítido, já que a Iniciativa Popular das dez medidas se tornou um pacote, 
evidenciando essa mistura de intenções institucionais em um projeto que, em verdade, deveria refletir apenas os interesses do povo.

\section{Análise crítica da tramitação institucional das iniciativas populares no Brasil}

A IPL no Brasil é um modelo que serve de instrumento à democracia indireta. As experiências demonstram que não é levada suficientemente a sério, provocando seu esvaziamento. Isto enseja a desvinculação do projeto de qualquer procedimento jurídico ou processo legislativo próprio, tornando-o objeto de manipulação. $\mathrm{O}$ atendimento dessas formalidades, ao contrário do que se possa pensar, não impede que se priorize a atuação popular. A formalidade por si só, garante a segurança jurídica necessária à idoneidade do procedimento crucial para formalizar de maneira fidedigna a intenção popular.

Algumas características reforçam a virada antidemocrática a que os projetos são submetidos quando ingressam em tramitação. As principais delas consistem (a) no controle que o acaba por deter, até quando da votação final pela aprovação ou rejeição que também é parlamentar e (b) na liberalidade para promover alterações nos projetos atribuída aos parlamentares, de maneira que o procedimento é regulado de forma a permitir uma relação com o Congresso de total permissibilidade a emendas modificativas e até mesmo substitutivas do projeto original.

Em qual medida estes projetos representam a vontade do povo, principalmente quando em poder dos parlamentares, é uma desconfiança válida. Apensamentos e alterações que descaracterizam a intenção popular, além da possibilidade de sua ampla modificação, tanto formal quanto substancial, contribuem para aumentar o vazio da atuação popular, que, no entanto, é preenchido pela atuação parlamentar, desvalendo a tarefa popular.

Além desses, outros aspectos procedimentais, ainda que periféricos, são importantes, tais como (a) a demora na tramitação, desde o ingresso até a apreciação, que no caso da primeira iniciativa popular perdurou por inacreditáveis dez anos; (b) o recebimento pelo Senado, segunda casa legislativa que não está autorizada por lei a receber a Iniciativa, porém ainda assim o fez; (c) a não verificação do cumprimento da exigência do número mínimo de assinaturas, requisito imprescindível para dar credibilidade, demonstrar autonomia e afirmar a legitimidade da Iniciativa Popular, dentre outros.

O esvaziamento do seu propósito também é provocado pela falta de características como celeridade. O impulso parlamentar acaba sendo decisivo para levar os projetos populares à votação final. O processo depende do peso dessa atuação, o que em tese não deveria ser 
necessário. A atribuição de autoria foi dada ao Executivo ou ao Senado em dois dos projetos tramitados. Permitir o começo da tramitação pelo Senado, restando este como responsável por sua autoria, é ignorar por completo o procedimento, representando quase um ato-falho originado do completo esvaziamento do instituto.

O problema é que essa prática reiterada de prescindir dos requisitos ameaça o fator credibilidade da IPL. Não se trata de julgar os responsáveis, e estes não seriam os propositores, que por óbvio desejavam, no caso da Ficha Limpa, obter o resultado do seu reconhecido esforço o quanto antes, mas sim, de problematizar essa prática.

Com relação ao conteúdo, o advento de uma norma que divulgue com maior clareza e objetividade as matérias que podem ser propostas mediante IPL, poderia evitar a criação de barreiras e confusões. Comumente, problemas com relação à matéria só são esclarecidos (ou não) no momento em que o projeto chega ao Congresso e é proposto à Câmara, o que contribui para tornar vazia a atuação popular.

O desvirtuamento ou descaracterização da Iniciativa dá-se igualmente por via do legado de autorias indevidas e promoção de mudanças textuais nos projetos, com contornos particulares, a ponto de desfigurá-la. Essas atribuições ilegais de autoria e mesmo aquelas feitas de forma legal, são modos de provocar seu desvirtuamento, por afastar o povo da noção simbólica de ser ele o titular do projeto e do seu acompanhamento. Todas estas alterações são capazes de desvirtuar o andamento da Iniciativa Popular, prejudicando e desprezando a questão concreta e simbólica da construção e da interação popular com o projeto durante a sua tramitação.

Para encerrar as impressões mais controversas, assinala-se a alteração substancial inicial promovida no PL 4850/2016, que resultou na decisão liminar oriunda do Mandado de Segurança interposto ao STF. A medida judicial teve como consequência a intervenção do Poder Judiciário no Legislativo, com intuito de corrigir esse tipo de alteração descaracterizadora do projeto. $\mathrm{O}$ julgado parece ter estabelecido uma base jurídica que representa um verdadeiro marco em relação ao procedimento. Há um indicação de que o Poder Judiciário entende como uma afronta ao direito constitucional o desvirtuamento da IPL pela inserção de emendas modificativas e substitutivas. Estes seriam os principais problemas enfrentados pelo instituto no Brasil, no que tange ao seu procedimento e a sua prática empírica.

\section{Considerações finais}


Neste momento, que encaminha o final do artigo, propõe-se uma reflexão sobre as vias de depreciação que a Iniciativa Popular Legislativa pode sofrer, observadas as práticas do caso brasileiro. Em suma, as principais dificuldades são arbitrárias e, em parte, regulamentadas no próprio Regimento Interno da Câmara dos Deputados, em completo desacordo com a Constituição e o espírito da Iniciativa Popular. O RICD ignora o caráter da participação popular e insere uma série de obstáculos inconstitucionais que inviabilizam o cumprimento desse propósito. Isso sem olvidar das ilegalidades que transgridem o próprio RI, como o caso da aceitação de projetos que deveriam ser recusados em função da matéria e a dispensa da verificação das assinaturas e das informações que as instruem, por alegada falta de estrutura institucional.

Ao contrário do que o senso comum possa prever, o elevado número de assinaturas exigido ou a suposta falta de capacidade popular para propor uma lei são argumentos que não se sustentam. Considerando as mencionadas dificuldades estruturais internas da própria casa legislativa para lidar com o primeiro projeto de iniciativa popular, além daquelas externas, tendo em vista a noção de "que a experiência brasileira é bem tímida no tocante à iniciativa popular" (MARCO, 2014, p. 143), ao menos foi possível constatar alguns aspectos positivos da primeira Iniciativa.

Através das impressões deixadas pela primeira experiência de Iniciativa Popular no Brasil, restou evidente em primeiro seu caráter instrumental, enquanto projeto democrático direcionado e específico para se atingir um objetivo popular. Em segundo, a demonstração de que a população é capaz de propor um projeto de lei articulado. Finalmente, o reconhecimento de que o povo pode atuar como sujeito ativo no processo legislativo.

A inegável inconstitucionalidade das exigências regimentais, com a consequente perda do caráter democrático a partir no início da tramitação, foram identificados como os principais focos prejudiciais à Iniciativa Popular no Brasil. De fato, esses aspectos procedimentais são prejudiciais à sua credibilidade e eficácia, pois de forma alguma o povo ratifica o projeto na sua versão final, mesmo diante da possibilidade de alteração substancial dos projetos mediante emendas parlamentares.

As variáveis que poderiam auxiliar na sua realização também não são favorecedoras do procedimento. As alternativas usadas para suprir as dificuldades e lacunas enfrentadas são práticas perversas que tornam seu procedimento flexível o suficiente a ponto de enfraquecer seu propósito. Suprir as eventuais falhas procedimentais com arbitrariedades facilita a aceitação do projeto, mas desfavorece a prática autônoma do povo e desmerece o método. 
A crítica contundente em relação ao desrespeito do procedimento, evidenciado pelas experiências, não insinua, contudo, uma supervalorização da técnica. Apenas alerta que o instrumento seria melhor aproveitado e democraticamente mais acessível se seu rito fosse claro, objetivo e respeitado pelos cidadãos e instituições. A imprevisibilidade procedimental revela um completo descaso com a correta aplicação do procedimento a ela destinado.

\section{Referências}

AMORIM, Diego. Presidente da Câmara afirmou que casa não precisa ouvir o povo? Nós checamos. O Globo, Rio de Janeiro, 02 de ago. de 2017. Disponível em: $<$ http://blogs.oglobo.globo.com/eissomesmo/post/presidente-da-camara-afirmou-que-casanao-precisa-ouvir-o-povo-nos-checamos.html>. Acesso em: 28 ago. 2017.

BRASIL. Congresso Nacional. Câmara dos Deputados. Comissão de Legislação Participativa. Of. Pres. Int. 088/2013 - CLP. Brasília, 28 ago. 2013. Disponível em: <http://www.camara.gov.br/proposicoesWeb/prop_mostrarintegra?codteor=1123193\&file name=Tramitacao-PLP+321/2013>. Acesso em: 27 mar. 2017.

BRASIL. Congresso. Câmara dos Deputados. Coordenação de Relacionamento, Pesquisa e Informação (CEDI). Câmara Responde: Projetos de lei de iniciativa popular. [mensagem institucional]. Mensagem recebida por < brunabotterocorrea@gmail.com > em 15 set. 2016a.

BRASIL. Constituição da República Federativa do Brasil - 1988. Diário Oficial [da]

República Federativa do Brasil, Brasília, DF, 5out. 1988. p. 1-32. Disponível em: <http://www.planalto.gov.br/ccivil_03/Constituicao/DOUconstituicao88.pdf>. Acesso em: 26 mar. 2017.

BRASIL. Congresso. Câmara dos Deputados. Dossiê do Projeto de Lei nº 1.517 de 1999. Poder Legislativo, Brasília, DF, 1999a. Disponível em:

<http://www.camara.gov.br/proposicoesWeb/prop_mostrarintegra;jsessionid=8949FE3E96A6 5A401572551D7ACF3867. proposicoesWebExterno2? codteor $=1124284 \&$ filename $=$ Dossie+PL+1517/1999>. Acesso em: 26 mar. 2017.

BRASIL. Congresso. Câmara dos Deputados. Dossiê do Projeto de lei no 4.146 de 1993. Disponível em:<http://www.camara.gov.br/proposicoesWeb/prop_mostrarintegra?codteor=1138635\&file name=Dossie+-PL+4146/1993>. Acesso em: 26 mar. 2017.

BRASIL. Congresso. Câmara dos Deputados. Inteiro Teor do Projeto de Lei $\mathbf{n}^{\mathbf{0}} \mathbf{7 . 0 5 3}$ de 2006. Poder Legislativo, Brasília, DF, 2006. P. 1-5.

Disponívelem:<http://www.camara.gov.br/proposicoesWeb/prop_mostrarintegra?codteor=39 6074\&filename=Tramitacao-PL+7053/2006>. Acesso em: 26 mar. 2017.

BRASIL. Lei complementar $\mathrm{n}^{\circ}$ 135, de 4 de junho de 2010. Altera a Lei Complementar no 64, de 18 de maio de 1990, que estabelece, de acordo com o $§ 9^{\circ}$ do art. 14 da Constituição 
Federal, casos de inelegibilidade, prazos de cessação e determina outras providências, para incluir hipóteses de inelegibilidade que visam a proteger a probidade administrativa e a moralidade no exercício do mandato. Diário Oficial [da] República Federativa do Brasil, Brasília, DF, 7 jun. 2010. p. 1-2. Disponível em: $<$ http://pesquisa.in.gov.br/imprensa/jsp/visualiza/index.jsp?data=07/06/2010\&jornal=1\&pagi na=1\&totalArquivos=80> . Acesso em: 26 mar. 2017.

BRASIL. Lei Ordinária $n^{\circ} 8.930$, de 6 de setembro de 1994. DA nova redação ao art. $1^{\circ}$ da Lei $\mathrm{n}^{\circ} 11.072$, de 25 de julho de 1990, que dispõe sobre os crimes hediondos, nos termos do art. $5^{\circ}$, inciso XLIII, da Constituição Federal, e determina outras providências. Diário Oficial [da] República Federativa do Brasil, Brasília, DF, 07set. 1994. p. 1. Disponível em: $<$ http://pesquisa.in.gov.br/imprensa/jsp/visualiza/index.jsp?jornal=1000\&pagina=1\&data=07/ 09/1994>. Acesso em: 26mar. 2017.

BRASIL. Lei Ordinária ${ }^{\circ} 9.840$, de 28 de setembro de 1999. Altera dispositivos da Lei ${ }^{\circ}$ 9.504, de 30 de setembro de 1997, e da Lei na 4.737, de 15 de julho de 1965 - Código Eleitoral. Diário Oficial [da] República Federativa do Brasil, Brasília, DF, 29 set. 1999b. p. 1. Disponível em: $<$ http://pesquisa.in.gov.br/imprensa/jsp/visualiza/index.jsp?jornal=1\&pagina $=65 \&$ data $=29 / 09$ /1999>. Acesso em: 26 mar. 2017.

BRASIL. Lei Ordinária n ${ }^{\circ} 11.124$, de 16 de junho de 2005. Dispõe sobre o Sistema Nacional de Habitação de Interesse Social - SNHIS, cria o Fundo Nacional de Habitação de Interesse Social - FNHIS e institui o Conselho Gestor do FNHIS Diário Oficial [da] República Federativa do Brasil, Brasília, DF, 17 jun. 2005. p. 1-3. Disponível em: $<$ http://pesquisa.in.gov.br/imprensa/jsp/visualiza/index.jsp?jornal=1\&pagina $=1 \&$ data $=17 /$ 06/2005>. Acesso em: 26mar. 2017.

BRASIL. Lei complementar $n^{\circ}$ 141, de 13 de janeiro de 2012. Diário Oficial [da] República Federativa do Brasil, Brasília, DF, 16jan. 2012a. p. 1. Disponível em: $<$ http://pesquisa.in.gov.br/imprensa/jsp/visualiza/index.jsp?jornal=1\&pagina $=1 \&$ data $=16 / 01 /$ 2012>. Acesso em: 27mar. 2017.

BRASIL. Lei Ordinária $n^{\circ} 12.741$, de 8 de dezembro de 2012. Dispõe sobre as medidas de esclarecimento ao consumidor, de que trata o $\S 5^{\circ}$ do artigo150 da Constituição Federal; altera o inciso III do art. $6^{\circ}$ e o inciso IV do art. 106 da Lei ${ }^{\circ} 8.078$, de 11 de setembro de 1990 Código de Defesa do Consumidor. Diário Oficial [da] República Federativa do Brasil, Brasília, DF, 10dez. 2012b. p. 1-2. Disponível em: <http://pesquisa.in.gov.br/imprensa/jsp/visualiza/index.jsp?data=10/12/2012\&jornal=1\&pagi na=1\&totalArquivos=232>. Acesso em: 26mar. 2017.

BRASIL. Congresso. Câmara dos Deputados. Dossiê do Projeto de Lei no 2.710 de 1992. Poder Legislativo, Brasília, DF, 1992a. Disponível em: $<$ http://www.camara.gov.br/proposicoesWeb/prop_mostrarintegra?codteor $=1140026 \&$ filena me=Dossie+-PL+2710/1992> . Acesso em: 14 jan. 2017.

BRASIL. Projeto de Lei Ordinária n ${ }^{\circ}$ 2.710, de 1992. Diário do Congresso Nacional [da] República Federativa do Brasil, Brasília, DF, 08 abril. 1992b. p. 6355-8. Disponível em: $<$ http://imagem.camara.gov.br/Imagem/d/pdf/DCD08ABR1992.pdf\#page=51 > . Acesso em: 26mar. 2017. 
BRASIL. Supremo Tribunal Federal. Medida Cautelar em Mandado de Segurança $\mathbf{n}^{\circ}$ 34.530. Impetrante: Eduardo Nantes Bolsonaro. Impetrada: Mesa Diretora da Câmara dos Deputados. Relator: Min. Luiz Fux. Brasília, 14 de dezembro de 2016b. Disponível em: <http://www.stf.jus.br/arquivo/cms/noticiaNoticiaStf/anexo/MS34530.pdf>. Acesso em: 26 dez. 2017.

CAVAlCANTE FILHO, J. T. Iniciativa Popular e Desvirtuamento do Projeto pelo Legislativo: limites e perspectivas de soluções no Brasil e no Direito Comparado. Brasília: Núcleo de Estudos e Pesquisas/CONLEG/Senado, Janeiro/2016 (Texto para Discussão no 223). Disponível em: www.senado.leg.br/estudos. Acesso em 30 de janeiro de 2017.

LEITE, Corália Thalita Viana Almeida; MAGALHÃES, Lívia Diana Rocha. Mídia e memória: do caso Daniella Perez à previsão do homicídio qualificado na Lei de Crimes Hediondos. Revista Eletrônica Direito e Política, Programa de Pós-Graduação Stricto Sensu em Ciência Jurídica da UNIVALI, Itajaí, v.8, n.3, 3º quadrimestre de 2013.

LIN, Nelson Shih Yien. Participação popular no legislativo federal - um estudo de seus mecanismos institucionais: emendas populares no processo constituinte, iniciativa popular de lei e Comissão de Legislação Participativa (CLP). 2010. 195 f. Dissertação (Mestrado em Ciência Política) - Faculdade de Filosofia, Letras e Ciências Humanas, Universidade de São Paulo, São Paulo.

MARCO, Nathalia Leone. Aspectos da iniciativa popular: "tímido" meio de participação democrática. Revista das Faculdades Metropolitanas Unidas (FMU) Direito, São Paulo, ano 28, n. 41, p.138-147, 2014.

MCCE, Assessoria de Comunicação do. Cartilha orientações para as eleições municipais 2016 - OPEM2016. Brasília: Ed. OAB, 2016.

MARQUES, Alan. Maia diz que pode mandar verificar assinaturas de pacote anticorrupção.

Folha de S. Paulo, São Paulo, 16 dez. 2016. Disponível em:

<http://www1.folha.uol.com.br/colunas/monicabergamo/2016/12/1841751maiadizquepodema ndarverificarassinaturasdepacoteanticorrupcao.shtml>. Acesso em: 26 mar. 2017.

MELCHIORI, Cíntia Ebner. Participação e representação política: a iniciativa popular de lei e o caso do movimento de combate à corrupção eleitoral. 2011. 132 f. Dissertação (Mestrado em Gestão e Políticas Públicas) - Escola de Administração de Empresas de São Paulo, Fundação Getúlio Vargas, São Paulo.

PAZ, Rosangela Dias Oliveira da. Fundo nacional de moradia popular: marco histórico de participação da união dos movimentos de moradia de São Paulo. 1996. 182f. Dissertação (Mestrado em Serviço Social) - Pontifícia Universidade Católica de São Paulo.

RIBEIRO JUNIOR, Ubergue. A iniciativa popular e sua relação com as iniciativas privativas do Presidente da República. Revista Jurídica, Brasília, v. 7, n. 72, p.01-35, maio, 2005.

SANTOS, Luiz Claudio Alves dos. A iniciativa popular das leis. E-Legis, n.01, p.05-09, $2^{\circ}$ semestre, 2008. 
SANTOS, Luiz Claudio Alves dos. A participação popular na iniciativa das leis no contexto da democracia representativa e da participação política no Brasil. 2009. 142 f. Dissertação (Mestrado em Ciência Política) - Centro de Formação, Treinamento e Aperfeiçoamento da Câmara dos Deputados, Instituto Universitário de Pesquisas do Rio de Janeiro, Rio de Janeiro.

SCHUMPETER, Joseph. Capitalismo, socialismo e democracia. Rio de Janeiro: Editora Fundo de Cultura, 1961.

Recebido em 12 nov. 2018 / Aprovado em 16 maio 2019

Para referenciar este texto:

CORREAA, Bruna Bottero; MARCHIORI NETO, Daniel Lena; FERRI, Caroline. Os projetos legislativos de iniciativa popular no Brasil. Prisma Jurídico, São Paulo, v. 18, n. 2, p. 169188, jul./dez. 2019. https://doi.org/10.5585/PrismaJ.v18n2.10917. 